\title{
Electric, Heating and Cooling Yields of Solar Collectors for Different Atmospheric Conditions and Tilt Angles
}

\author{
Hussein M. Taqi Al-Najjar \\ University of Baghdad \\ College of Engineering \\ Energy Engineering Department
}

\begin{abstract}
In this paper, a study was carried out for the effect of local atmospheric condition and tilt angle on the energy yields of solar collectors at selected latitudes. A computer program was developed for that purpose to find the daily average, monthly, seasonal and annual energy profiles based on Klein model and Erbs correlation. Using generic system of solar collector at due south, hybrid energy yields: electric, heating and cooling were obtained. As a case study, the results were presented for latitudes $30^{\circ}-37^{\circ} \mathrm{N}$. Optimum tilt angles were found to be within $0^{\circ}$ to $66^{\circ}$ which nonlinearly depends on the relevant time period of the year and atmospheric condition. Two important findings were concluded. First, optimum angles would be larger for better atmospheric conditions with greater shifts during winter period while summer months are of less sensitivity. This shift was $10^{\circ}-14^{\circ}$ for winter monthly energy, $0^{\circ}-8^{\circ}$ for summer monthly energy, $11^{\circ}-13^{\circ}$ for total annual and heating energy and $1^{\circ}-3^{\circ}$ for total cooling energy. Second, deviations in the angles of commonly used empirical formulas were noticed to be larger in summer period and higher latitudes. These deviations were in the range of $-10^{\circ}$ to $+20^{\circ}$ as compared to the corresponding values of present study. Finally, average energy values were 6055,1700 and $2370 \mathrm{MJ} / \mathrm{m}^{2}$ for annual, heating and cooling yields respectively.
\end{abstract}

\section{Keywords}

solar collector, energy profile, electric heating cooling yields, atmospheric condition, optimum tilt angle.

\section{INTRODUCTION}

Currently, the global status of energy supply and use is in danger due to challenges of energy security, climate change and sustainable development. This imposes a pressing need to accelerate the deployment of advanced energy technologies to address above issues. However, this step requires research and development (R\&D), governmental regulations and investment decisions [1-3].

Among many types of renewable and sustainable energy technologies, solar collectors are most promising energy conversion systems for solving the global challenges of energy. Solar collectors have two distinct features. First, solar energy is abundant enough, in many regions of the world, to drive solar collectors. Second, solar collectors can have electric and/or thermal energy yields [1-3]. There are a large family of solar collectors of different types, design, structure and characteristics with a broad range of applications mainly in buildings and industry sectors [4-7]. They are used for supplying electricity as on-grid or off-grid power systems. Also, solar collectors are utilized as on-site systems for hot water, industrial process heat and air conditioning. Thus, solar collectors can be used to provide electric, heating and cooling (EHC) energy yields for different applications [8-14]. Such applications will reduce the need for fossil fuels which accordingly can have good impact on energy systems [1-3].

By the year of 2015, the world electric and thermal capacities from solar collectors can be extrapolated as $220 \mathrm{GW}$ and 400 $\mathrm{GW}_{\text {th }}$ respectively [15]. For on-grid electric generation, more than 50 large solar power plants (> $100 \mathrm{MW}$ capacity) are spread around the world mainly in China, USA, Spain, Germany, India, UAE and other countries [16]. For solar thermal installations, water and air heating systems were installed in China $\left(118 \mathrm{GW}_{\mathrm{th}}\right)$, Europe $\left(36 \mathrm{GW}_{\mathrm{th}}\right)$ and the United States and Canada $\left(16 \mathrm{GW}_{\mathrm{th}}\right)$ as by the end of 2010 . As solar cooling, in Singapore, at the United World College, a cooling system of $1.47 \mathrm{MW}$ capacity and collector field of $3900 \mathrm{~m}^{2}$ was completed for operation in 2011 [3]. New installations for solar power and thermal applications are expected to continue to increase for electric, heating and cooling uses [1-3].

Orientation of solar collectors, by tilt and azimuth angles, is an important parameter for maximizing their energy yields. Numerous research papers and studies were published for calculating, experimentally and theoretically, the optimum angles and the corresponding gains of different solar energy systems for various countries such as in Middle East, China, Europe and the USA [17-26]. For solar collectors at due south, optimum tilt angles for monthly, winter, summer and annual setting are often calculated using simple empirical formulae which depend primarily on latitude of the location and the relevant time period [4, 5 and 27]. However, these correlations are specified with no dependence on local atmospheric condition. Among many published papers, two particular studies, Christensen and Barker [25] and Lubitz [26], found that for many sites across the United States $\left(25^{\circ}-\right.$ $50^{\circ} \mathrm{N}$ ) of different climate conditions, lower annual tilt angle values were associated with higher latitudes and lower average sky clearness index.

The aim of the present work is to investigate the effect of local atmospheric condition and tilt angle on the profiles of energy of a generic system of solar collector at due south. Daily average, monthly, seasonal and annual yields for electric, heating and cooling (EHC) uses will be considered at different atmospheric conditions and tilt angles. For that purpose, a computer program is to be developed based on Klein model and Erbs correlation. Then, a case study will be applied for latitudes $30^{\circ}-37^{\circ} \mathrm{N}$ which includes the whole region of Iraq.

\section{ENERGY CALCULATIONS OF SOLAR COLLECTORS}

A solar collector can be of either photovoltaic (PV) or dark metal absorber. A PV collector produces electric energy directly, while the latter is a thermal collector that delivers direct heat. The PV collector can also yield heat energy. The 
heat energy of the thermal collector can be transformed to electric energy by an additional conversion system of heat engine and electric generator.

On the other hand, adding some thermal cooling system, sorption or desiccant, the heat of either collector can be converted to cooling energy [4, 5]. Fig.1 explains the different energy yields: electric, heating and cooling (EHC) of a generic system of solar collector. The three gray blocks are additional energy conversion systems. Numbers shown in the figure are the corresponding nominal efficiencies and coefficient of performance (COP) [1-3]. Actual values depend on the specific system design and its operating conditions.

The amount of energy yield Y from a generic system of solar collector per unit area for a given period of time is related to the solar energy $\mathrm{S}$ received by the collector per unit area for that period multiplied by the overall efficiency $\eta_{\mathrm{ov}}$ of the energy conversion which is the combined efficiency of the solar collector and the additional conversion system if any. Thus:

$\mathrm{Y}=\eta_{\mathrm{ov}} \mathrm{S}$

Energy yield is usually calculated on hourly and daily basis. However, for design consideration, daily average values are mostly needed. Then, according to eqn (1), the average solar energy for the collector is to be firstly found. Klein model is widely used for that purpose $[4,5]$. Based on that model, the average energy $\mathrm{S}$ for a collector of tilt angle $\mathrm{T}$ is related to the collector energy of zero-tilt angle $S_{0}$ and its components $S_{1}$ and $\mathrm{S}_{2}$, the geometric factor $\mathrm{R}$ and the reflectance $f$ of the surroundings as:

$\mathrm{S}=\mathrm{RS}_{1}+\left(\frac{1+\cos \mathrm{T}}{2}\right) \mathrm{S}_{2}+\left(\frac{1-\cos \mathrm{T}}{2}\right) f \mathrm{~S}_{\mathrm{o}}$

The factor $\mathrm{R}$ for a collector at due south in the northern hemisphere is given by:

$\mathrm{R}=\frac{\cos \phi^{\prime} \cos \delta \sin \omega_{\mathrm{s}}^{\prime}+\omega_{\mathrm{s}}^{\prime} \sin \phi^{\prime} \sin \delta}{\cos \phi \cos \delta \sin \omega_{\mathrm{s}}+\omega_{\mathrm{s}} \sin \phi \sin \delta}$

The apparent site latitude $\phi^{\prime}$, solar declination angle $\delta$, sunset hour angle $\omega_{\mathrm{s}}$ and apparent sunset hour angle $\omega_{\mathrm{s}}$ ' are found by:

$\phi^{\prime}=\phi-\mathrm{T}$

$\delta=23.45^{\circ} \sin \left[\frac{360}{365}(284+\mathrm{n})\right]$

$\omega_{\mathrm{s}}=\cos ^{-1}(-\tan \phi \tan \delta)$

$\omega_{\mathrm{s}}^{\prime}=\min \left\{\begin{array}{l}\cos ^{-1}\left(\omega_{\mathrm{s}}\right) \\ \cos ^{-1}\left(-\tan \phi^{\prime} \tan \delta\right)\end{array}\right.$

Where $\phi$ is the site latitude and $\mathrm{n}$ is the number of day in year Finally, the remaining parameters to be calculated are $S_{0}, S_{1}$ and $S_{2}$ which are depend on the local atmospheric condition. In fact, $S_{o}$ is a fraction of the extraterrestrial energy $S_{x}$ due to atmospheric scattering and absorption. A sky clearness index $\mathrm{K}_{\mathrm{T}}$ is introduced as a measure of transmittance of the atmosphere: $0<\mathrm{K}_{\mathrm{T}}<1$; then:

$\mathrm{K}_{\mathrm{T}}=\mathrm{S}_{\mathrm{o}} / \mathrm{S}_{x}$

The extraterrestrial energy is found by:

$\begin{aligned} \mathrm{S}_{x}=\frac{118.109}{\pi}(1+ & \left.0.033 \cos \frac{360}{365} \mathrm{n}\right) \cdot\left(\cos \phi \cos \delta \sin \omega_{\mathrm{s}}\right. \\ & \left.+\omega_{\mathrm{s}} \sin \phi \sin \delta\right)\end{aligned}$
As $S_{1}$ and $S_{2}$ are the two components, beam and diffuse, of $S_{0}$; then:

$\mathrm{S}_{\mathrm{o}}=\mathrm{S}_{1}+\mathrm{S}_{2}$

To find these components, Erbs correlation [4,5], which relates the fraction of energy component to clearness index, is used with $0.3 \leq \mathrm{K}_{\mathrm{T}} \leq 0.8$ as follows:

For $\omega_{\mathrm{s}} \leq 81.4^{\mathrm{o}}$ :

$\mathrm{S}_{2} / \mathrm{S}_{\mathrm{o}}=1.391-3.560 \mathrm{~K}_{\mathrm{T}}+4.189 \mathrm{~K}_{\mathrm{T}}^{2}-2.137 \mathrm{~K}_{\mathrm{T}}^{3}$

For $\omega_{\mathrm{s}}>81.4^{\circ}$ :

$\mathrm{S}_{2} / \mathrm{S}_{\mathrm{o}}=1.311-3.022 \mathrm{~K}_{\mathrm{T}}+3.427 \mathrm{~K}_{\mathrm{T}}^{2}-1.821 \mathrm{~K}_{\mathrm{T}}^{3}$

It can be noticed from above equations that the daily average yields of a generic system of solar collector at due south is a function of five parameters: site location, time of the year, local atmospheric condition, tilt angle of the solar collector, and overall efficiency of the energy conversion system. Using daily average values, the monthly, seasonal (winter and summer) and annual yields can be found by multiplying daily values with the corresponding number of days. For a given energy system and location, the energy yields will be related to time period, atmospheric condition and tilt angle. This relation is to be investigated in the present work as will be explained.

Apart from above detailed equations, empirical formulas that are independent of atmospheric condition are commonly used to find tilt angles for maximum energy yields. For monthly tilt angle, a set of 12 relations were given by [27]. However, more simple formulas are derived for monthly, annual and seasonal tilt angles respectively as follows $[4,5]$ :

$$
\begin{aligned}
& \mathrm{T}=|\phi-\delta| \\
& \mathrm{T}=\phi \\
& \mathrm{T}=\phi \pm 15^{\circ}
\end{aligned}
$$

Where plus and minus signs correspond to winter and summer seasons respectively.

\section{METHODOLOGY}

Following the procedure of previous section, a computer program was developed to calculate the energy of a generic system of solar collector at due south. Normal reflectance of surroundings (with no snow) $f=0.2$ was assumed. Three atmospheric conditions were considered: poor, fair and good of $\mathrm{K}_{\mathrm{T}}=0.3,0.5$ and 0.7 respectively. For each of these conditions, the tilt angle of solar collector was changed from $0^{\circ}$ to $90^{\circ}$ to find daily average energy profiles based on the mean day of each month. Then, monthly, seasonal (heating and cooling) and annual energy yields along with the corresponding optimum tilt angles were found to one degree accuracy. The total energy for a period of monthly average ambient temperature $\leq 15^{\circ} \mathrm{C}$ is termed as "heating energy" for the winter season. While the total energy for a period of monthly average ambient temperature $\geq 30{ }^{\circ} \mathrm{C}$ is termed as "cooling energy" for the summer season. Monthly average ambient temperatures over many years were taken from [28]. Values of empirical formulas, eqn (12-14), were compared with the corresponding observed angles of the present study to calculate the resultant deviations.

All results were shown for three site latitudes: $30^{\circ} \mathrm{N}, 33.23^{\circ} \mathrm{N}$ and $37^{\circ} \mathrm{N}$ which corresponds to southern, middle and northern areas of Iraq respectively. It should be noted that electric, heating and cooling (EHC) energy yields can be 
obtained, using eqn (1), by multiplying calculated energy values with the specific overall efficiency of the associated conversion system, see Fig.1.

\section{RESULTS AND DISCUSSION}

For mid latitude $33.23^{\circ} \mathrm{N}$ (Baghdad), the results are shown in Figures 2, 3 and 4. The profiles of energy as daily average values per month with the tilt angle are shown in Fig.2 for the three atmospheric conditions. Numbers on profiles are month number. It can be noticed that profiles have maximum energy at tilt angles between $0^{\circ}$ to $63^{\circ}$ depending on the month and the atmospheric condition. Maximum energy values can be classified by month with descending order in five groups: June, July and May, August and April, September and March, October and February, and finally November, January and December. Maximum values are found to be 220 - 880 $\mathrm{MJ} / \mathrm{m}^{2}$. On the other hand, the tilt angle for maximum energy is being larger in the above order of months as solar declination is decreasing. With respect to atmospheric condition, optimum tilt angles are positively shifted by $0^{\circ}-7^{\circ}$ for group 1 and group 2 as atmospheric condition is changed from poor to good. For the remaining groups, the corresponding shift is $10^{\circ}-13^{\circ}$.

Annual energy profiles of the solar collector are shown in Fig.3 as function of tilt angle for the three atmospheric conditions. Maximum annual values were 3.473, 6.068 and $8.814 \mathrm{GJ} / \mathrm{m}^{2}$ at $20^{\circ}, 28^{\circ}$ and $32^{\circ}$ tilt angles for poor, fair and good atmospheric conditions respectively. Optimum tilt angle is shifted by $12^{\circ}$ with better atmospheric conditions.

The profiles of total heating and cooling energy of solar collector are drawn versus tilt angle in Fig.4 for the three atmospheric conditions. Maximum heating energy was found to be $0.686,1.393$ and $2.205 \mathrm{GJ} / \mathrm{m}^{2}$ at $45^{\circ}, 55^{\circ}$ and $58^{\circ}$ tilt angles for poor, fair and good atmospheric conditions respectively. The tilt angle shift is $13^{\circ}$. The maximum cooling energy values were $1.394,2.329$ and $3.268 \mathrm{GJ} / \mathrm{m}^{2}$ at $5^{\circ}, 7^{\circ}$ and $8^{\circ}$ tilt angles for the three atmospheric conditions respectively. Here, the shift in tilt angle is small $\left(3^{\circ}\right)$.

Maximum energy yields (monthly, annual, heating and cooling) along with the corresponding tilt angles for mid latitude are tabulated in Table $\mathbf{1}$ for the different atmospheric conditions. It can be noticed that the deviations in tilt angle of empirical formulas are in the range $-10^{\circ}$ to $+13^{\circ}$.

For southern and northern areas, the results are shown in Table 2 and Table 3 respectively. The corresponding optimum tilt angles are $0^{\circ}$ to $66^{\circ}$. It can be noticed that for southern area, the shift in optimum tilt angle with atmospheric condition is $0^{\circ}-6^{\circ}$ and $10^{\circ}-14^{\circ}$ for summer and winter half of the year respectively. The deviations of empirical formulas are $-10^{\circ}$ to $+13^{\circ}$. For northern area, the summer and winter shifts are in the range of $0^{\circ}-8^{\circ}$ and $12^{\circ}-14^{\circ}$ respectively. The deviations are $-6^{\circ}$ to $+20^{\circ}$.

Fig.5 and Fig.6 show the monthly variation of optimum tilt angle at poor and good atmospheric conditions for the two extreme latitudes $\left(30^{\circ} \mathrm{N}\right.$ and $\left.37^{\circ} \mathrm{N}\right)$ respectively. It indicates monthly deviations of $-7^{\circ}$ to $+12^{\circ}$ for $30^{\circ} \mathrm{N}$ and $-6^{\circ}$ to $+16^{\circ}$ for $37^{\circ} \mathrm{N}$. It can be found that the shift is being greater with better atmospheric conditions. However, summer period is of less sensitivity. On the other hand, deviations are larger in summer period and higher latitude.

Finally, the summary of whole results is shown in Table 4 which gives the range of shifts and deviations in optimum tilt angles along with the average of maximum energy yields for latitudes $30^{\circ} \mathrm{N}-37^{\circ} \mathrm{N}$.

\section{CONCLUSION}

In this work, energy yields of generic system of solar collector were calculated theoretically for different atmospheric conditions and tilt angles at latitudes $30^{\circ} \mathrm{N}$ to $37^{\circ} \mathrm{N}$, see Tables 1, 2 and 3. To the best knowledge of the author, no previous published paper was found for the effect of local atmospheric condition on monthly, seasonal and annual energy profiles of tilted solar collector at least for the location of Iraq. On the basis of this study, the following conclusions have been drawn:

- Two important findings were concluded in this paper: first, optimum tilt angles are positively shifted with better atmospheric conditions. Greater shifts were found during winter period while summer months have negligible change. Second, the deviations in the tilt angle of the empirical formulas as compared to observed values of present paper are positive or negative. Negative values were found at better atmospheric conditions and lower latitudes during winter period. However, most deviations were positive with larger values at higher latitude in summer period.

- The shift was in the range of $0^{\circ}-14^{\circ}$; with summer shift $0^{\circ}-8^{\circ}$ and winter shift $10^{\circ}-14^{\circ}$. The deviation was $-10^{\circ}$ to $+20^{\circ}$, see Table 4 .

- Optimum tilt angles were $0^{\circ}-66^{\circ}$ which are function of local atmospheric condition and time period of the year.

- For maximum annual energy, the usual setting of tilt angle to be equal to site latitude is found to be only applied for good atmospheric condition. However, for other atmospheric conditions, the tilt angle is to be at $5^{\circ}-14^{\circ}$ lower.

- The tilt angle for maximum heating energy was of strong dependence on atmospheric conditions. The shift is maximum $\left(=13^{\circ}\right)$ with $-10^{\circ}$ to $+8^{\circ}$ deviation.

- For maximum cooling energy, the corresponding tilt angle is close to zero $\left(0^{\circ}-8^{\circ}\right)$ of negligible shift with atmospheric condition.

- The average of maximum energy yields: monthly, annual, heating and cooling were $535 \mathrm{MJ} / \mathrm{m}^{2}, 6055$ $\mathrm{MJ} / \mathrm{m}^{2}, 1700 \mathrm{MJ} / \mathrm{m}^{2}$ and $2370 \mathrm{MJ} / \mathrm{m}^{2}$ respectively. 


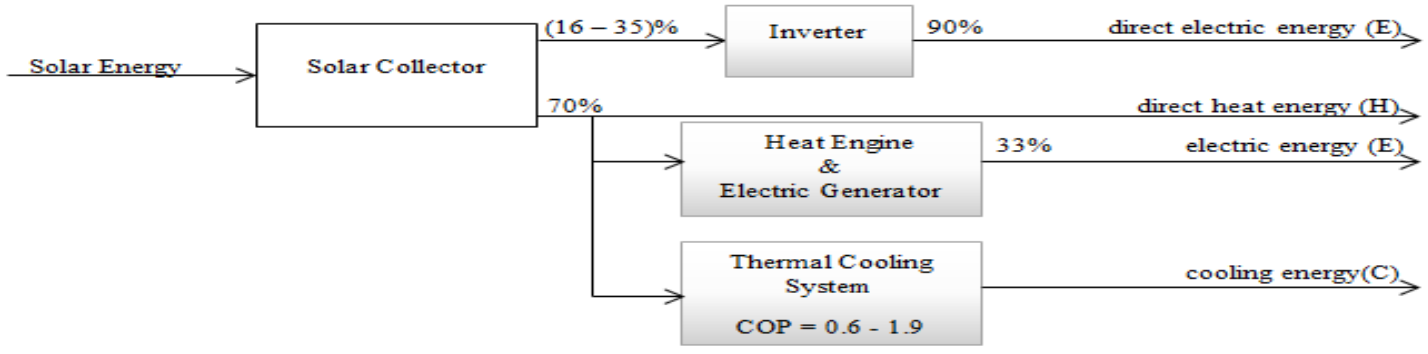

Fig 1: Block diagram of energy yields of a generic system of solar collector.

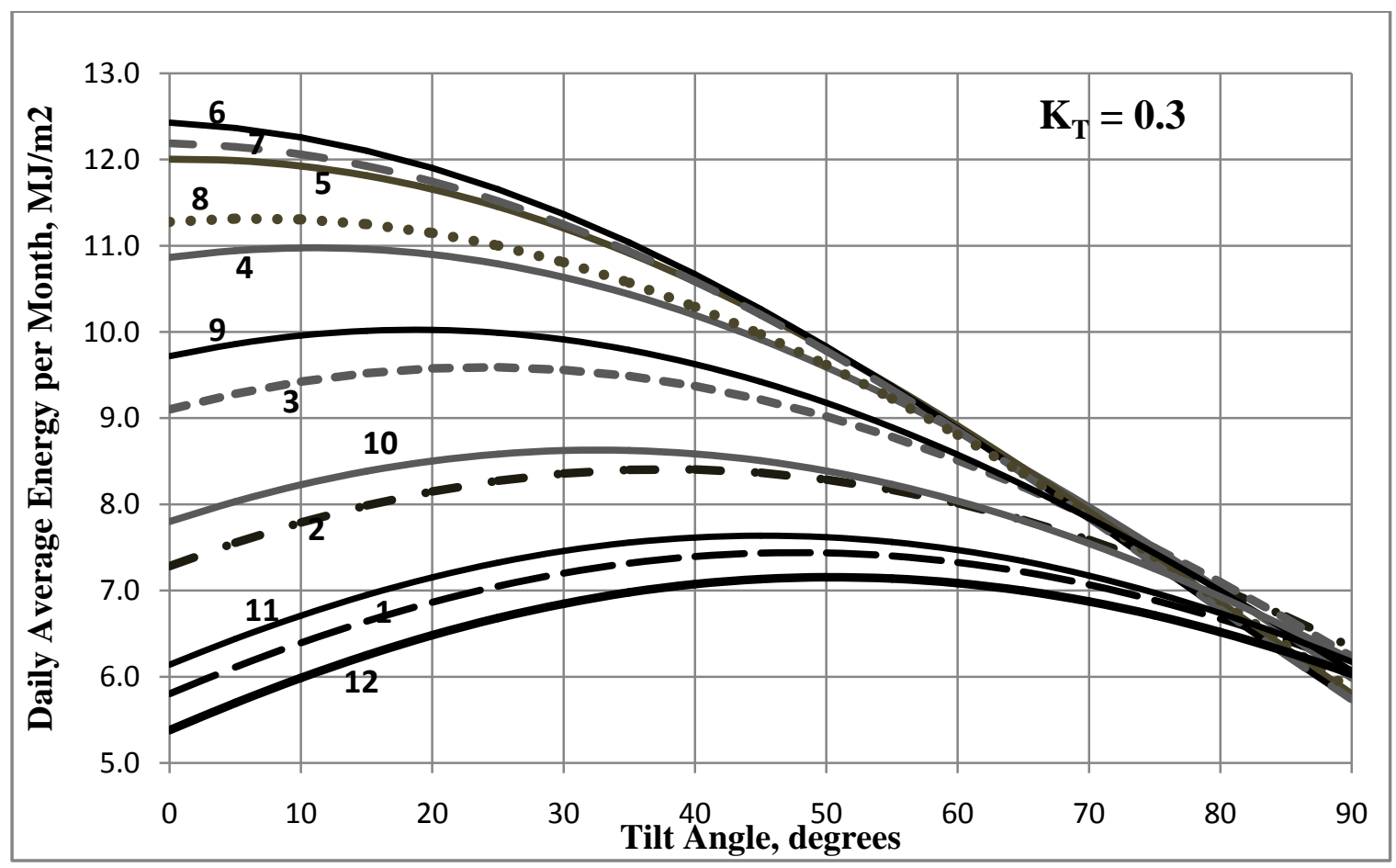

(a)

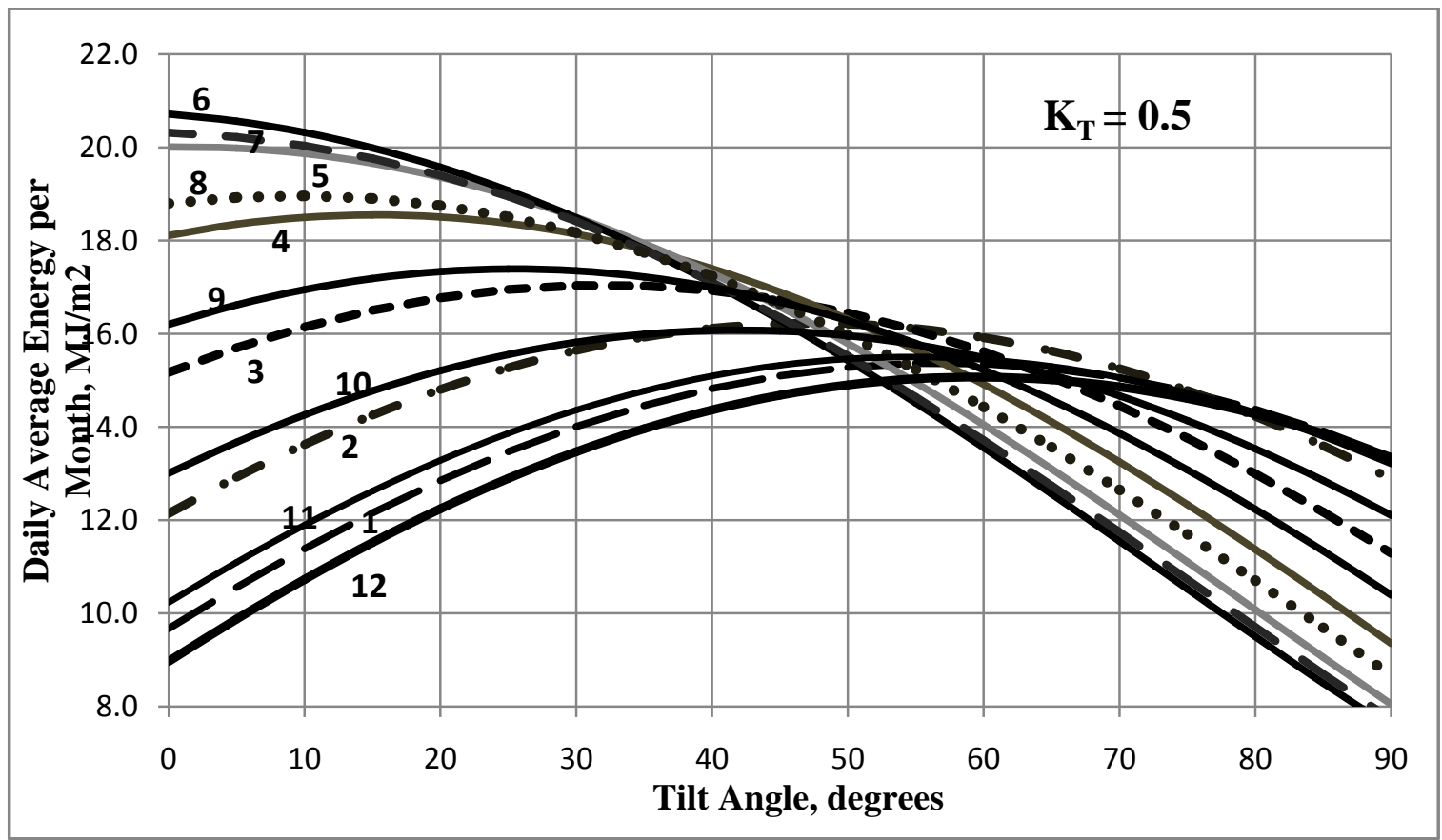

(b) 


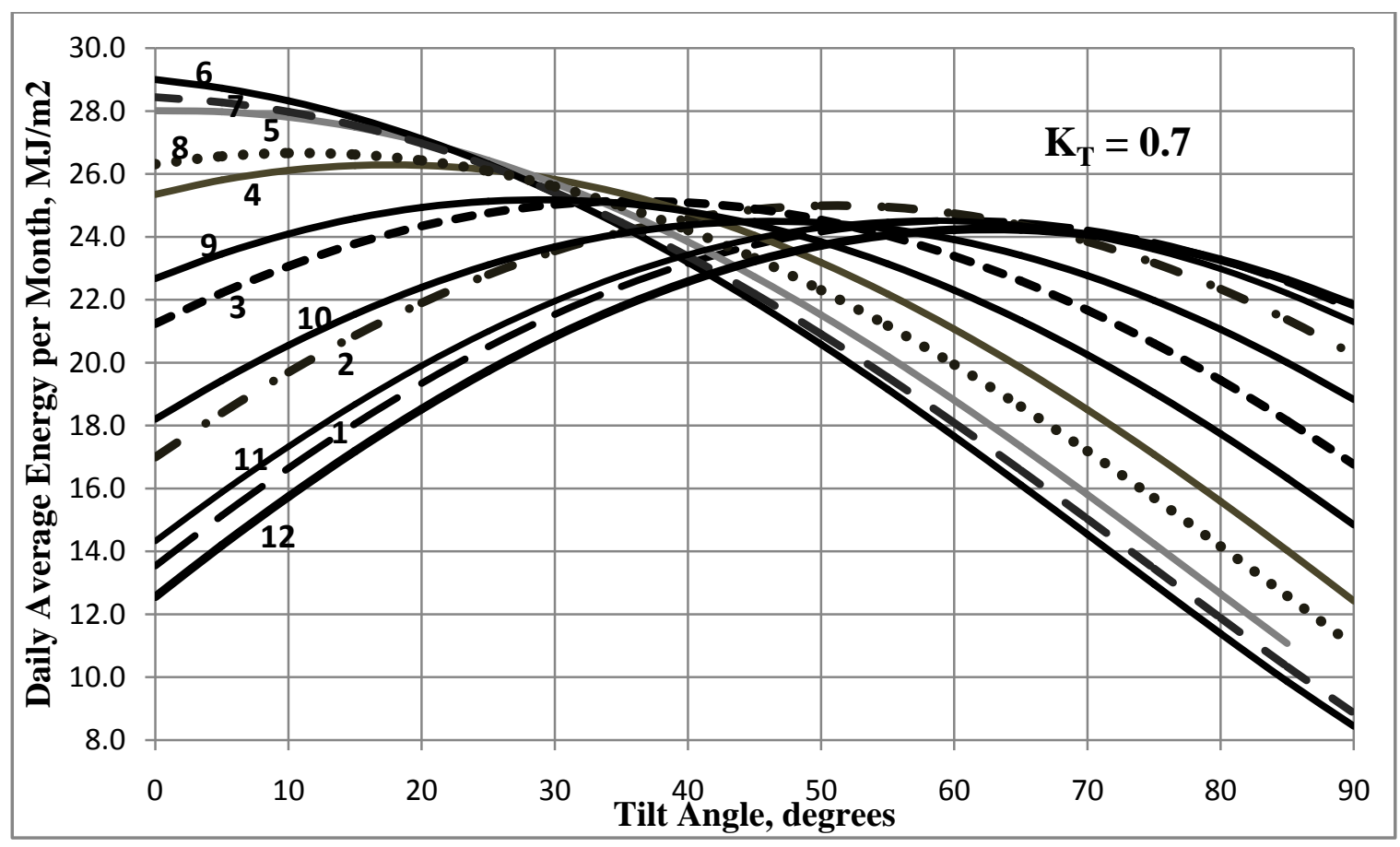

(c)

Fig 2: Daily average energy per month with collector tilt angle for mid latitude with: (a) $K_{T}=0.3(b) K_{T}=0.5(c) K_{T}=0.7$.

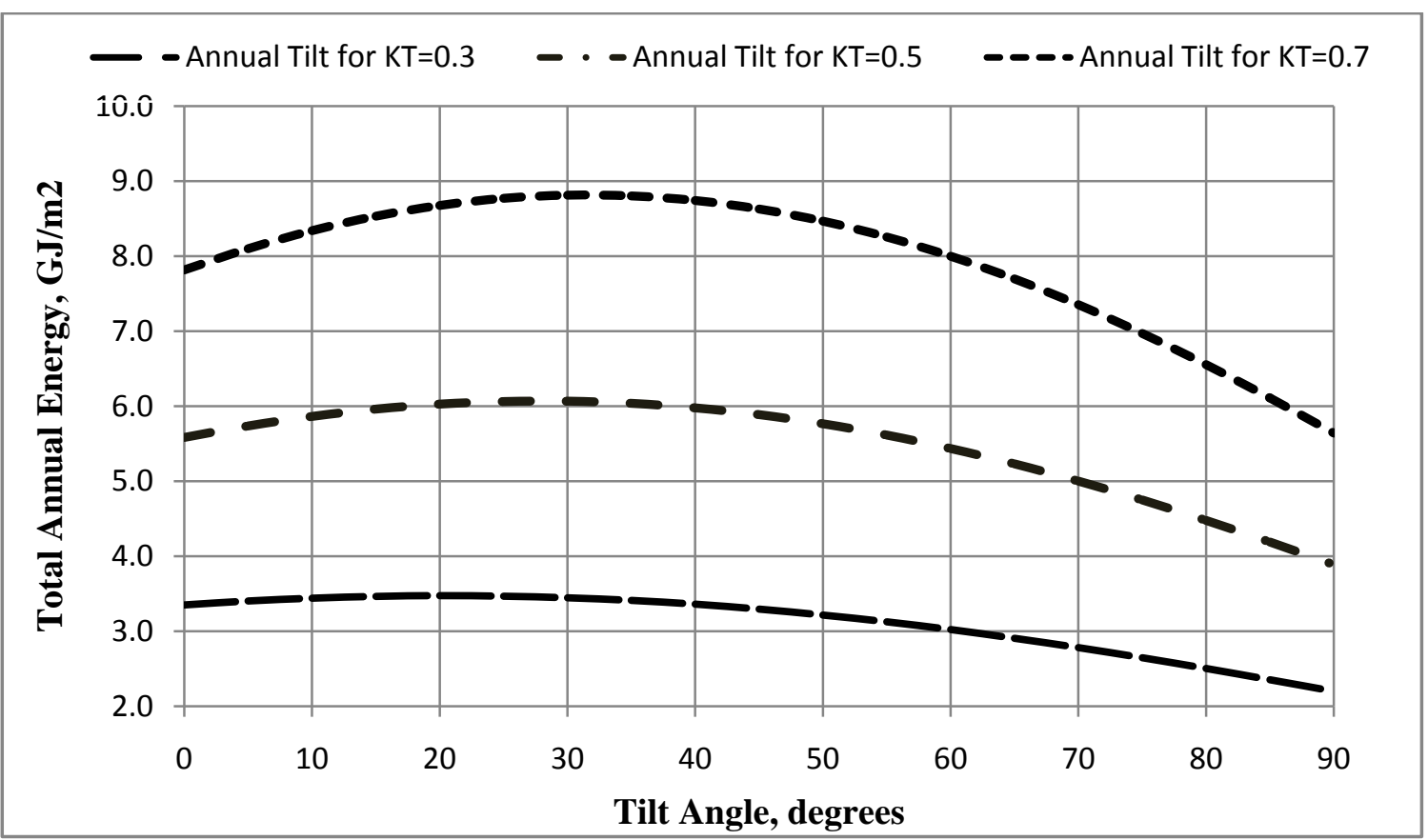

Fig 3: Total annual energy with collector tilt angle for mid latitude with $K_{T}=0.3, K_{T}=0.5$ and $K_{T}=0.7$. 


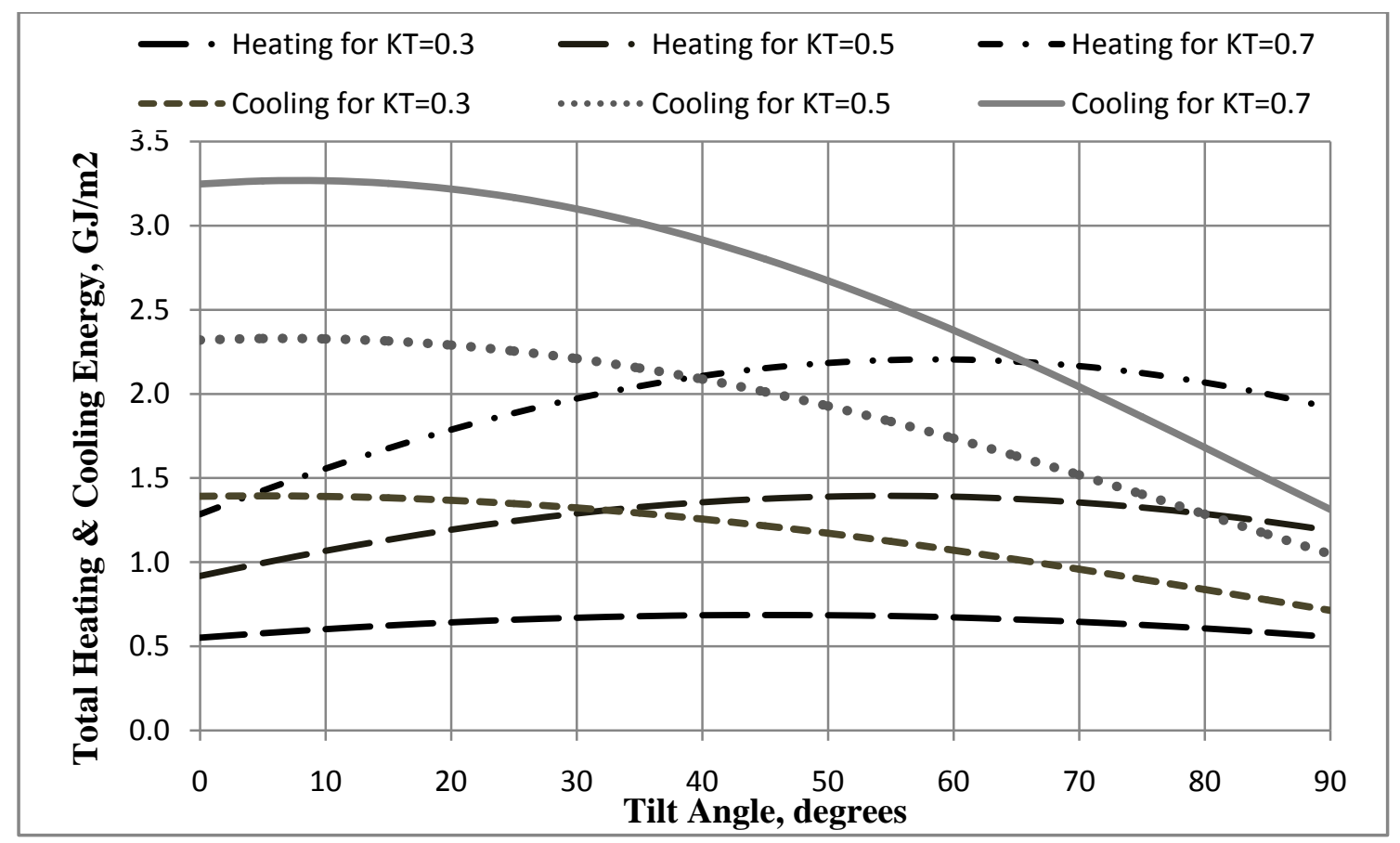

Fig 4: Total heating and cooling with collector tilt angle for mid latitude with $K_{T}=0.3, K_{T}=0.5$ and $K_{T}=0.7$.

Table 1. Maximum energy yields $\left(\mathrm{MJ} / \mathrm{m}^{2}\right)$ and optimum tilt angles for mid latitude with $K_{\mathrm{T}}=0.3, K_{\mathrm{T}}=0.5$ and $K_{\mathrm{T}}=0.7$.

(a) Monthly values

\begin{tabular}{|c|c|c|c|c|c|c|c|c|}
\hline \multirow{2}{*}{ month } & \multirow{2}{*}{ use } & \multicolumn{2}{|c|}{$\mathrm{K}_{\mathrm{T}}=0.3$} & \multicolumn{2}{|c|}{$\mathrm{K}_{\mathrm{T}}=0.5$} & \multicolumn{2}{|c|}{$\mathrm{K}_{\mathrm{T}}=0.7$} & \multirow{2}{*}{$\begin{array}{l}\text { tilt angle of } \\
\text { equation( }(12)\end{array}$} \\
\hline & & value & tilt angle & value & tilt angle & value & tilt angle & \\
\hline Jan & $\mathrm{EH}$ & 230.6 & 48 & 476.5 & 57 & 760.1 & 60 & 54 \\
\hline Feb & $\mathrm{EH}$ & 235.4 & 38 & 454.2 & 47 & 699.9 & 51 & 46 \\
\hline Mar & $\mathrm{E}$ & 297.4 & 24 & 528.3 & 32 & 779.3 & 36 & 36 \\
\hline Apr & $\mathrm{E}$ & 329.3 & 11 & 556.5 & 15 & 788.7 & 18 & 24 \\
\hline May & $E$ & 372.1 & 1 & 630.3 & 1 & 868.5 & 1 & 14 \\
\hline Jun & $\mathrm{EC}$ & 372.9 & 0 & 621.5 & 0 & 870.0 & 0 & 10 \\
\hline Jul & $\mathrm{EC}$ & 377.9 & 0 & 629.8 & 0 & 881.7 & 0 & 12 \\
\hline Aug & EC & 350.8 & 7 & 587.8 & 9 & 826.7 & 11 & 20 \\
\hline Sep & $\mathrm{EC}$ & 300.8 & 19 & 521.7 & 25 & 755.4 & 29 & 31 \\
\hline Oct & $\mathrm{E}$ & 267.5 & 33 & 498.3 & 42 & 759.3 & 46 & 43 \\
\hline Nov & $\mathrm{E}$ & 229.1 & 45 & 465.0 & 55 & 735.4 & 58 & 52 \\
\hline Dec & EH & 221.8 & 50 & 467.1 & 59 & 751.8 & 63 & 56 \\
\hline \multirow{3}{*}{ Sum } & $\mathrm{EHC}$ & 3586 & - & 6427 & - & 9477 & - & - \\
\hline & $\mathrm{EH}$ & 688 & - & 1398 & - & 2212 & - & - \\
\hline & $\mathrm{EC}$ & 1402 & - & 2361 & - & 3334 & - & - \\
\hline
\end{tabular}

(b) Total annual, heating and cooling values

\begin{tabular}{|c|c||c|c||c|c||c|c||c||}
\hline \multirow{2}{*}{ Time } & \multirow{2}{*}{ use } & \multicolumn{2}{c||}{$\mathrm{K}_{\mathrm{T}}=0.3$} & \multicolumn{2}{c||}{$\mathrm{K}_{\mathrm{T}}=0.5$} & \multicolumn{3}{c||}{$\mathrm{K}_{\mathrm{T}}=0.7$} \\
\cline { 3 - 9 } & & value & tilt angle & value & tilt angle & value & $\begin{array}{c}\text { angle of } \\
\text { tilt angle } \\
\text { equations } \\
(13 \text { and 14) }\end{array}$ \\
\hline Annual & EHC & 3473 & 20 & 6068 & 28 & 8814 & 32 & 33 \\
\hline Winter & EH & 686 & 45 & 1393 & 55 & 2205 & 58 \\
\hline Summer & EC & 1394 & 5 & 2329 & 7 & 3268 & 8 & 18 \\
\hline
\end{tabular}


Table 2. Maximum energy yields $\left(\mathrm{MJ} / \mathrm{m}^{2}\right)$ and optimum tilt angles for southern latitude with $K_{T}=0.3, K_{T}=0.5$ and $K_{T}=0.7$.

(a) Monthly values

\begin{tabular}{|c|c|c|c|c|c|c|c|c|}
\hline \multirow{2}{*}{ month } & \multirow{2}{*}{ use } & \multicolumn{2}{|c|}{$\mathrm{K}_{\mathrm{T}}=0.3$} & \multicolumn{2}{|c|}{$\mathrm{K}_{\mathrm{T}}=0.5$} & \multicolumn{2}{|c|}{$\mathrm{K}_{\mathrm{T}}=0.7$} & \multirow{2}{*}{$\begin{array}{l}\text { tilt angle of } \\
\text { equation(12) }\end{array}$} \\
\hline & & value & tilt angle & value & tilt angle & value & tilt angle & \\
\hline Jan & $\mathrm{EH}$ & 243.8 & 45 & 492.2 & 54 & 776.5 & 58 & 51 \\
\hline Feb & $\mathrm{EH}$ & 243.2 & 34 & 456.3 & 43 & 698.5 & 48 & 43 \\
\hline Mar & $\mathrm{E}$ & 306.2 & 22 & 537.9 & 29 & 786.5 & 33 & 32 \\
\hline Apr & $\mathrm{E}$ & 333.5 & 9 & 561.1 & 13 & 792.1 & 15 & 21 \\
\hline May & EC & 372.1 & 0 & 620.1 & 0 & 868.2 & 0 & 11 \\
\hline Jun & $\mathrm{EC}$ & 370.1 & 0 & 616.9 & 0 & 863.7 & 0 & 7 \\
\hline Jul & $\mathrm{EC}$ & 376.3 & 0 & 627.1 & 0 & 878.0 & 0 & 9 \\
\hline Aug & $\mathrm{EC}$ & 353.4 & 5 & 590.5 & 7 & 828.7 & 8 & 17 \\
\hline Sep & EC & 307.7 & 16 & 529.2 & 23 & 761.0 & 26 & 28 \\
\hline Oct & $\mathrm{E}$ & 278.4 & 30 & 510.2 & 39 & 769.2 & 43 & 40 \\
\hline Nov & $\mathrm{E}$ & 241.4 & 42 & 479.2 & 52 & 749.5 & 55 & 49 \\
\hline Dec & $\mathrm{EH}$ & 235.4 & 47 & 483.9 & 56 & 770.2 & 60 & 53 \\
\hline \multirow{3}{*}{ Sum } & $\mathrm{EHC}$ & 3662 & - & 6505 & - & 9542 & - & - \\
\hline & $\mathrm{EH}$ & 722 & - & 1433 & - & 2245 & - & - \\
\hline & $\mathrm{EC}$ & 1780 & - & 2984 & - & 4200 & - & - \\
\hline
\end{tabular}

(b) Total annual, heating and cooling values

\begin{tabular}{|c|c||c|c||c|c||c|c||c||}
\hline \multirow{2}{*}{ Time } & \multirow{2}{*}{} & use & \multicolumn{2}{c||}{$\mathrm{K}_{\mathrm{T}}=0.3$} & \multicolumn{2}{c||}{$\mathrm{K}_{\mathrm{T}}=0.5$} & \multicolumn{3}{c||}{$\mathrm{K}_{\mathrm{T}}=0.7$} & $\begin{array}{c}\text { tilt angle of } \\
\text { equations } \\
(13 \text { and 14) }\end{array}$ \\
\cline { 2 - 10 } & & value & tilt angle & value & tilt angle & value & tilt angle \\
\hline Annual & EHC & 3556 & 18 & 6155 & 25 & 8882 & 29 & 30 \\
\hline Winter & EH & 720 & 42 & 1427 & 52 & 2237 & 55 & 45 \\
\hline Summer & EC & 1772 & 2 & 2955 & 3 & 4139 & 3 & 15 \\
\hline
\end{tabular}

Table 3. Maximum energy yields $\left(\mathrm{MJ} / \mathrm{m}^{2}\right)$ and optimum tilt angles for northern latitude with $K_{T}=0.3, K_{T}=0.5$ and $K_{T}=0.7$.

(a) Monthly values

\begin{tabular}{|c|c|c|c|c|c|c|c|c|}
\hline \multirow{2}{*}{ month } & \multirow{2}{*}{ use } & \multicolumn{2}{|c|}{$\mathrm{K}_{\mathrm{T}}=0.3$} & \multicolumn{2}{|c|}{$\mathrm{K}_{\mathrm{T}}=0.5$} & \multicolumn{2}{|c|}{$\mathrm{K}_{\mathrm{T}}=0.7$} & \multirow{2}{*}{$\begin{array}{l}\text { tilt angle of } \\
\text { equation(12) }\end{array}$} \\
\hline & & value & tilt angle & value & tilt angle & Value & tilt angle & \\
\hline Jan & $\mathrm{EH}$ & 215.1 & 52 & 457.4 & 61 & 739.4 & 64 & 58 \\
\hline Feb & $\mathrm{EH}$ & 222.9 & 41 & 440.8 & 51 & 688.0 & 55 & 50 \\
\hline Mar & $\mathrm{EH}$ & 286.2 & 27 & 516.4 & 36 & 770.2 & 40 & 39 \\
\hline Apr & $\mathrm{E}$ & 323.3 & 13 & 550.0 & 18 & 784.0 & 21 & 28 \\
\hline May & $\mathrm{E}$ & 371.2 & 3 & 619.3 & 4 & 867.7 & 5 & 18 \\
\hline Jun & EC & 375.0 & 0 & 624.9 & 0 & 874.9 & 0 & 14 \\
\hline Jul & $\mathrm{EC}$ & 378.5 & 0 & 630.9 & 0 & 883.2 & 0 & 16 \\
\hline Aug & $\mathrm{EC}$ & 346.9 & 9 & 583.4 & 13 & 823.5 & 15 & 24 \\
\hline Sep & $\mathrm{E}$ & 291.8 & 21 & 512.0 & 29 & 748.2 & 33 & 35 \\
\hline Oct & $E$ & 254.3 & 36 & 483.8 & 46 & 747.1 & 50 & 47 \\
\hline Nov & $\mathrm{EH}$ & 214.6 & 49 & 447.8 & 58 & 717.7 & 62 & 56 \\
\hline Dec & $\mathrm{EH}$ & 205.8 & 54 & 446.7 & 63 & 728.4 & 66 & 60 \\
\hline \multirow{3}{*}{ Sum } & EHC & 3486 & - & 6313 & - & 9372 & - & - \\
\hline & $\mathrm{EH}$ & 1145 & - & 2309 & - & 3644 & - & - \\
\hline & $\mathrm{EC}$ & 1100 & - & 1839 & - & 2582 & - & - \\
\hline
\end{tabular}


(b) Total annual, heating and cooling values

\begin{tabular}{|c|c||c|c||c|c||c|c||c||}
\hline \multirow{2}{*}{ time } & \multirow{2}{*}{} & \multirow{2}{*}{ use } & \multicolumn{2}{c||}{$\mathrm{K}_{\mathrm{T}}=0.3$} & \multicolumn{2}{c||}{$\mathrm{K}_{\mathrm{T}}=0.5$} & \multicolumn{3}{c||}{$\mathrm{K}_{\mathrm{T}}=0.7$} & $\begin{array}{c}\text { tilt angle of } \\
\text { equations } \\
\text { (13 and 14) }\end{array}$ \\
\cline { 2 - 10 } & & value & tilt angle & value & tilt angle & value & tilt angle \\
\hline Annual & EHC & 3366 & 23 & 5949 & 31 & 8714 & 35 & 37 \\
\hline Winter & EH & 1133 & 44 & 2281 & 54 & 3600 & 57 & 52 \\
\hline Summer & EC & 1099 & 2 & 1832 & 3 & 2566 & 4 & 22 \\
\hline
\end{tabular}

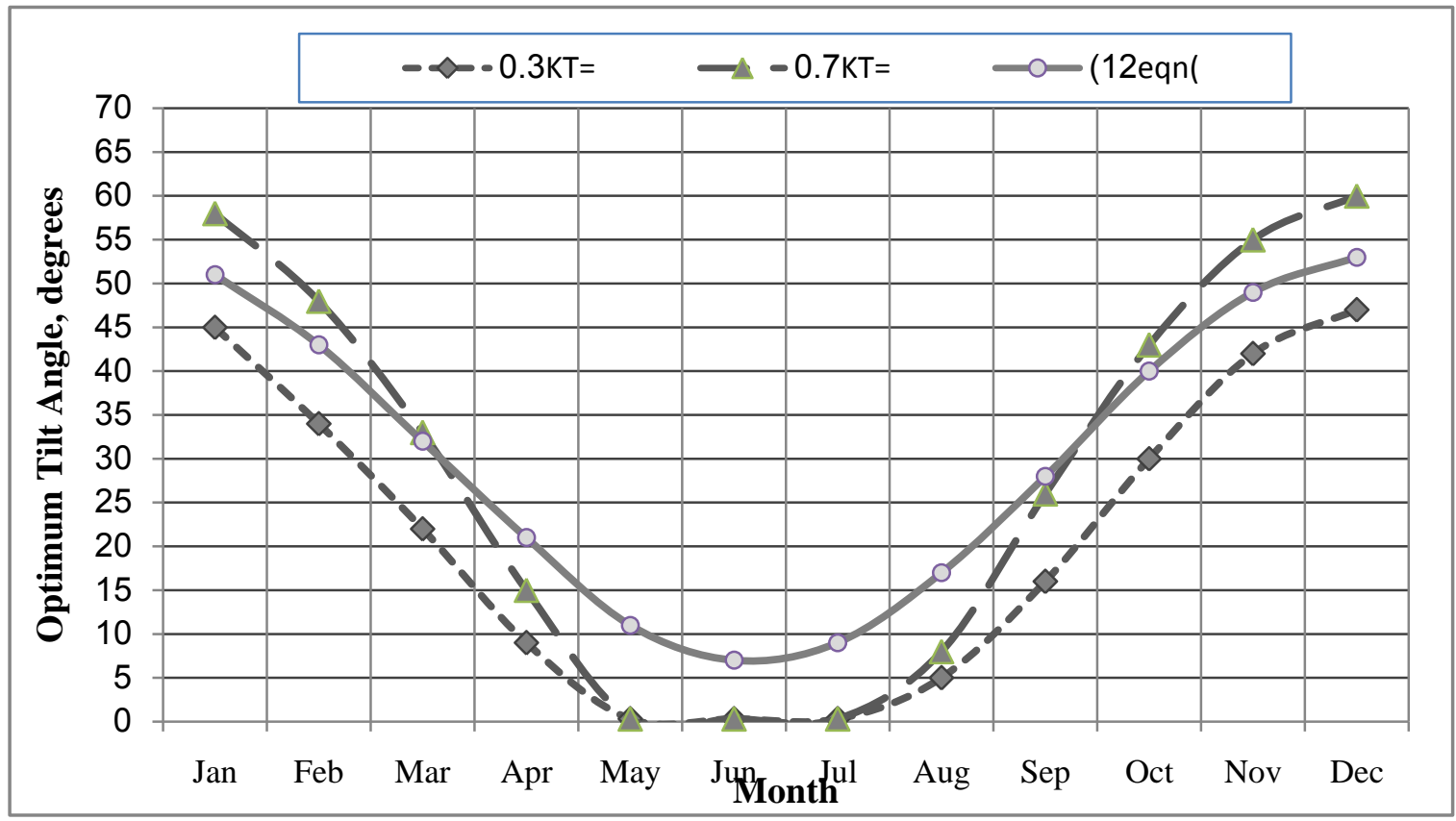

Fig 5: Monthly variation of optimum tilt angle for southern latitude with $K_{T}=0.3$ and $K_{T}=0.7$.

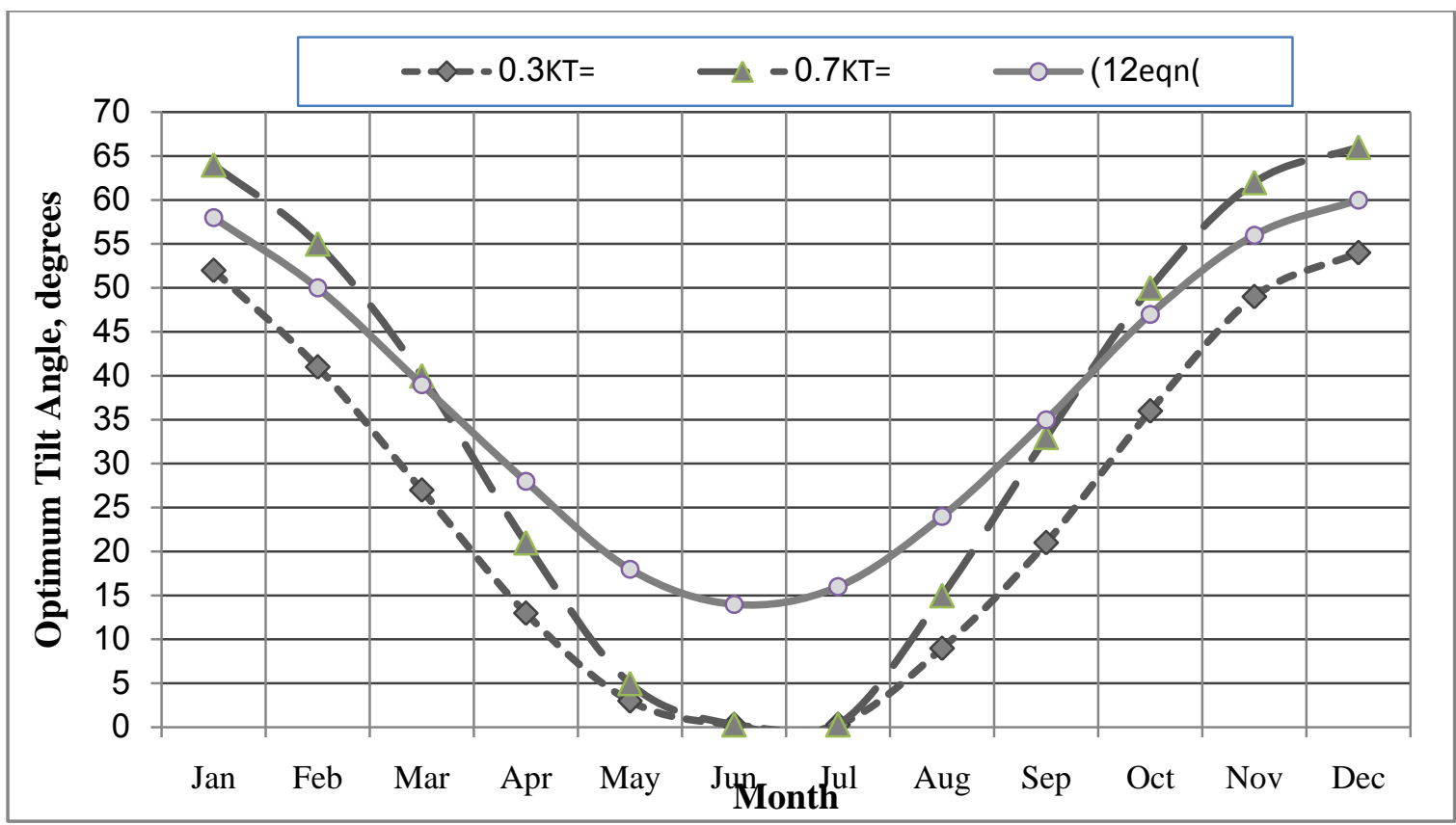

Fig 6: Monthly variation of optimum tilt angle for northern latitude with $K_{T}=0.3$ and $K_{T}=0.7$. 
Table 4. Summary of results

\begin{tabular}{|c|c|c|c|}
\hline Time Period & Shift & Deviation & $\begin{array}{c}\text { Energy Yield, } \\
\mathrm{MJ} / \mathrm{m}^{2}\end{array}$ \\
\hline Monthly & $\begin{array}{c}\text { Summer: } 0^{\circ}-8^{\circ} \\
\text { Winter: } 10^{\circ}-14^{\circ}\end{array}$ & $-7^{\circ}$ to $+16^{\circ}$ & 535 \\
\hline Annual & $11-12^{\circ}$ & $1^{\circ}-14^{\circ}$ & 6055 \\
\hline Heating & $13^{\circ}$ & $-10^{\circ}$ to $+8^{\circ}$ & 1700 \\
\hline Cooling & $1^{\circ}-3^{\circ}$ & $10^{\circ}-20^{\circ}$ & 2370 \\
\hline
\end{tabular}

\section{REFERENCES}

[1] International Energy Agency, 2014, Technology Roadmap: Solar Photovoltaic Energy.

[2] International Energy Agency, 2014, Technology Roadmap: Solar Thermal Electricity.

[3] International Energy Agency, 2012, Technology Roadmap: Solar Heating and Cooling.

[4] Duffie, J. A. and Beckman, W. A., 2013, Solar Engineering of Thermal Processes, $4^{\text {th }}$ edition, John Wiley and Sons Inc.

[5] Kalogirou, S. A., 2013, Solar Energy Engineering: Processes and Systems, $2^{\text {nd }}$ edition, Elsevier Inc.

[6] Tiwari, G. N. and Dubey, S., 2010, Fundamentals of Photovoltaic Modules and Their Applications, RSC publishing.

[7] Kalogirou, S. A., 2014, Solar Thermal Collectors and Applications, Progress in Energy and Combustion Science 30, 231-295.

[8] Rodriguez-Aumente, P.A., Rodriguez-Hidalgo, M.D.C., Nogueira, J.I., Lecuona, A. and Venegas, M.D.C., 2013, District Heating and Cooling for Business Buildings in Madrid, Applied Thermal Engineering 50 (2), 14961503.

[9] Fang, X., and Li, D, 2013, Solar Photovoltaic and Thermal Technology and Applications in China, Renewable and Sustainable Energy Reviews 23, 330340.

[10] Malogneta, D., Szklo, A., Soria, R., Schaeffer, R., and Borba, B.S.M.C., 2014, Potential and Impacts of Concentrated Solar Power (CSP) Integration in the Brazilian Electric Power System, Renewable Energy 68, 223-235.

[11] Herrando, M., Markides, C. N. and Hellgardt, K., 2014, UK-Based Assessment of Hybrid PV and Solar-Thermal Systems for Domestic Heating and Power: System Performance, Applied Energy 122, 288-309.
[12] Salwan, S. D. and Sopian, K., 2012, Electricity Generation of Hybrid PV/Wind System in Iraq, Renewable Energy 35, 1303-1307.

[13] Ghaith, F. A., and Abu Sitta, R., 2014, Energy Analyses of an Integrated Solar Powered Heating and Cooling Systems in UAE, Energy and Buildings 70, 117-126.

[14] Fasfous, A., Asfar, J., Al-Salaymeh, A., Sakhrieh, A., Alhamamre, Z., Al-bawwab, A. and Hamdan, M., 2013, Potential of Utilizing Solar Cooling in the University of Jordan, Energy Conversion and Management 65, 729735 .

[15] REN21, 2014, Renewables 2014: Global Status Report.

[16] http://www.wikipedia.org.

[17] Ahmed, N., Sheikh, A. K., Gandhidasan, P. and Elshafie, E., 2015, Modeling, Simulation and Performance Evaluation of a Community Scale PVRO Water Desalination System Operated by Fixed and Tracking PV Panels: A Case Study for Dhahran City, Saudi Arabia, Renewable Energy 75, 433-447.

[18] Skeiker, K., 2009, Optimum Tilt Angle and Orientation for Solar Collectors in Syria, Energy Conversion and Management 50 (9) 2439-2448.

[19] Al-Najjar, H. M. T., 2015, Study of Energy Gains by Orientation of Solar Collectors in Baghdad City, Journal of Engineering, Vol.21, No.10.

[20] Al Tarabsheh, A., Etier, I. and Nimrat, A., 2012, Energy Yield of Tracking PV Systems in Jordan, International Journal of Photoenergy, Vol.2012, Article ID890183, 5 pages.

[21] Khorasanizadeh, H., Mohammadi, K. and Mostafaeipour, A., 2014, Establishing a Diffuse Solar Radiation Model for Determining the Optimum Tilt Angle of Solar Surfaces in Tabass, Iran, Energy Conversion and Management 78, 805-814.

[22] Eke, R. and Senturk, A., 2012, Performance Comparison of a Double-Axis Sun Tracking Versus Fixed PV System, Solar Energy 86, 2665-2672. 
[23] Li, Z., Liu, X. and Tang, R., 2010, Optical Performance of Inclined South-North Single Axis Tracked Solar Panels, Energy 35 (6), 2511-2516.

[24] Huld, T., Cebecauer, T., Suri, M. and Dunlop, E., 2010, Analysis of One Axis Tracking Strategies for PV Systems in Europe, Progress in Photovoltaics: Research and Applications 18 (3), 183-194.

[25] Christensen, C.B and Barker, G.M, 2001, Effects of Tilt and Azimuth on Annual Incident Solar Radiation for United States Location. In Proc. solar forum: solar energy: the power to choose, Washington, DC, April 2125.
[26] Lubitz, W. D., 2011, Effect of Manual Tilt Adjustments on Incident Irradiance on Fixed and Tracking Solar Panels, Applied Energy 88, 1710-1719.

[27] Nijegorodov, N., Devan, K.R.S., Jain, P.K. and Carlsson, S., 1994, Atmospheric Transmittance Models and An Analytical Method to Predict the Optimum Slope of An Absorber Plate, Variously Orientated at Any Latitude, Renewable Energy 4, 529-543.

[28] http://www.weatherbase.com. 